\title{
Kierkegaard y el idealismo: lineamientos de su proximidad histórico-especulativa
}

\author{
María José Binetti
}

\section{Introducción}

$\mathrm{K}$ puede ser un poeta romántico, cuyo canto se dirige a un ideal inalcanzable. Él puede ser también un ferviente defensor del cristianismo ortodoxo, cuando no un teólogo, pastor y predicador de la Iglesia luterana dinamarquesa. Puede ser, además, un fino psicólogo de la existencia, un cuidadoso crítico de arte, un periodista polémico o un panfletario agitador de las calles de Copenhague. En último lugar, aunque no menos relevante, Kierkegaard puede ser el gran filósofo del espíritu subjetivo y, como tal, un filósofo afín al idealismo. El objetivo central del presente trabajo consistirá entonces en mostrar los grandes puntos de convergencia entre Kierkegaard y el idealismo absoluto.

Desde el punto de vista crítico, postular la cercanía de Kierkegaard con el idealismo no deja de significar un desafío historiográfico, con cierta dosis de provocación al ya instalado discurso "antiidealista" del existencialismo en general y de Kierkegaard en particular. En efecto, sabido es que la exégesis kierkegaardiana está dominada por el tópico de su antiidealismo, amparado en gran parte de los propios escritos de Kierkegaard. En líneas generales, los críticos aducen que, a diferencia del idealismo absoluto, Kierkegaard defendería la lógica aristotélica, la trascendencia divina y la dogmática cristiana. ${ }^{1}$

${ }^{1} C f$. Niels Thulstrup y M. M. Thulstrup, eds., Kierkegaard and Speculative Idealism. Copenhague, C. A. Reitzels Boghandel, 1979, vol. 4, p. 100 (Bibliotheca kierkegaardiana); $c f$. también N. Thulstrup, Kierkegaards forhold til Hegel og til den spekulative idealisme indtil 1846. Copenhague, Gyldendal, 1967. 
No obstante, en contraposición con esta lectura dominante, siempre han habido voces proclives a considerar la cercanía del pensamiento kierkegaardiano con el idealismo. El último y mayor análisis en esta dirección lo constituye la obra de Jon Stewart, para quien la interpretación antiidealista de Kierkegaard peca de ser una simplificación acrítica y ahistórica. ${ }^{2} \mathrm{~J}$. Stewart sostiene la profunda y positiva influencia particularmente de G. W. F. Hegel sobre Kierkegaard y, llegando más lejos, sobre el existencialismo en general. ${ }^{3}$ Por lo mismo se inclinan, por ejemplo, autores como M. C. Taylor, M. Theunissen y M. Westphal, P. Ricour y S. Žižek, ${ }^{4}$ aunque salvando matices y diferencias entre ambos pensadores. Por su parte, los análisis del pensamiento hegeliano suelen confirmar la misma interpretación. ${ }^{5}$ Hay también otra línea de lectura que si bien reconoce la profunda influencia de Hegel sobre Kierkegaard, la lee en el sentido negativo de una dialéctica truncada, sin mediación ni reconciliación final, lo cual convertiría al pensamiento kierkegaardiano en un subjetivismo abstracto, arbitrario e infeliz. Entre tales intérpretes podríamos mencionar, por ejemplo, a Th. Adorno, J. Wahl, J. L. Marsh o L. J. Start. ${ }^{6}$ Por último, hay quienes se ocuparon específicamente de la proximidad de Kierkegaard con

${ }^{2}$ Cf. Jon Stewart, Kierkegaard's Relations to Hegel Reconsidered. Nueva York, Cambridge University Press, 2003; J. Stewart, Kierkegaard and His Contemporaries. The Culture of Golden Age Denmark. Berlín/Nueva York, Walter de Gruyter, 2003; J. Stewart, "Kierkegaard as Hegelian", en Enrahonar, 29, 1998, pp. 147-152; J. Stewart, "Kierkegaard and Hegel on Faith and Politics", en Kierkegaardiana, 20, 1999, pp. 251 254; J. Stewart, Idealism and Existentialism. Hegel and Nineteenth- and TwentiethCentury European Philosophy. Londres/Nueva York, Continuum, 2010.

${ }^{3}$ Cf. J. Stewart, Idealism and Existentialism. Hegel and Nineteenth-and TwentiethCentury European Philosophy y J. Stewart, ed., The Hegel Myths and Legends. Evanston, Universidad de Northwestern, 1996.

${ }^{4}$ Cf. M. C. Taylor, Journeys to Selfhood: Hegel \& Kierkegaard. Berkeley, Universidad de California, 1980; M. Theunissen, Kierkegaard's Concept of Despair. Trad. de Barbara Harshav y Helmut Illbruck. Princeton, Universidad de Princeton, 2005; M. Westphal, "Kierkegaard and the Role of Reflection in Second Immediacy", en P. Cruysberghs, J. Taels, K. Verstrynge, Immediacy and Reflection in Kierkegaard's Thought. Lovaina, Universidad de Lovaina, 2003, pp. 159-179; P. Ricour, "Philosopher après Kierkegaard", en Les Cahiers de Philosophie, vol. 8-9, 1989, pp. 285-300; S. Žižek, The Parallax View. Cambridge/Londres, The Mit Press, 2006, p. 15.

${ }^{5}$ Cf. J. N. Findlay, Hegel: A Re-examination. Nueva York, Oxford University, 1958, p. 18; T. Pinkard, Hegel's Phenomenology. The Sociality of Reason. Cambridge, Universidad de Cambridge, 1994, pp. 70 y 333; H. Schmitz, Hegel als Denker der Individualität. Meisenheim/Glan, Verlag Anton Hain, 1957, p. 167.

${ }^{6}$ Cf. T. W. Adorno, Kierkegaard. Trad. de R. J. Vernengo. Caracas, Monte Ávila, 1969, pp. 45 y ss.; J. Wahl, Études kierkegaardiennes. 2a. ed., París, J. Vrin, 1949, pp. 144 y ss.; J. L. Marsh, Hegel and Kierkegaard: A Dialectical and Existential Contrast. Evanston, Universidad de Northwestern, 1971 y L. J. Start, Kierkegaard and Hegel. Universidad de Siracusa, 1953. 
los románticos alemanes, ${ }^{7}$ con F. J. W. Schelling ${ }^{8}$ o con los jóvenes hegelianos de izquierda. ${ }^{9}$

A diferencia de cualquiera de estos análisis, el objetivo de las siguientes páginas consistirá en mostrar la influencia positiva que sobre el dinamismo subjetivo kierkegaardiano tiene el idealismo absoluto como gran corriente de pensamiento, asumiendo sus núcleos metafísicos fundamentales y distinguiendo a la vez acentos y matices diferenciales propios de Kierkegaard, cuya filosofía resultaría así un idealismo sui generis. Nos proponemos mostrar por qué, en tanto que idealista, la filosofía kierkegaardiana podría describirse como un espiritualismo dialéctico, relacional y mediador de su propia identidad, cuyo punto de partida reside en la consciencia reflexiva del yo, y cuyo punto de llegada lo constituye la autoconciencia absoluta del singular.

Dado que nuestra consideración será fundamentalmente metafísica y que entendemos, además, que hay en Kierkegaard una sola metafísica, espiritualista y dinámica, a cuyos momentos y determinaciones subjetivas responde la discriminación de modos y figuras de la comunicación kierkegaardiana, por esta razón apelaremos tanto a las obras seudónimas como a los Diarios o Papeles de manera indiscriminada. Antes bien, intentaremos discriminar la determinación o instancia metafísica expresada por ellos, en lugar de atender a la figura representativa del sujeto supuesto de la enunciación conceptual, incluso cuando se tratara de la representación del propio Kierkegaard como autor. La distinción de seudónimos y tipos de comunicación quedará, por lo tanto, supuesta en la discriminación metafísico-conceptual de

${ }^{7}$ Cf. J. Stewart, ed., Kierkegaard and his German Contemporaries. III. Literature and Aesthetics. Burlington/Hampshire, Ashgate, 2007; W. Rehm, Kierkegaard und der Verführer. Múnich, Hermann Rinn, 1949; H. Fenger, Kierkegaard. The Myths and their Origins. Trad. de G. C. Schoolfield, New Haven/Londres, Universidad de Yale, 1980, p. 305; M. Katz, Kierkegaard's Critique of the German Romantics. Evanston, Universidad de Northwestern, 1991; J. Wahl, "Kierkegaard et le romantisme", en Symposion Kierkegaardianum. Copenhague, Munksgaard, 1955, pp. 297-302.

${ }^{8}$ Cf. J. Stewart, ed., Kierkegaard and his German Contemporaries. I: Philosophy. Burlington/Hampshire, Ashgate, 2007; M. Heidegger, Nietzsche. Trad. de J. L. Vernal. 3a. ed. Barcelona, Destino, 2000, vol. II, pp. 387-90; S. Spera, "L'influsso di Schelling nella formazione del giovane Kierkegaard", en Archivio di Filosofia, 1, 1976, pp. 73-108; J. Colette, "Kierkegaard et Schelling", en Kairos, 10, 1997, pp. 19-31; A. Ejsing, "Kierkegaard and Schelling: The Life of Becoming", en Kierkegaardiana, 23, 2004, pp. 113-125.

${ }^{9} \mathrm{Cf}$. J. Stewart, ed., Kierkegaard and his German Contemporaries. II: Theology. Burlington/Hampshire, Ashgate, 2007; K. Löwith, De Hegel a Nietzsche. La quiebra revolucionaria del pensamiento en el siglo XIX. Marx y Kierkegaard. Trad. E. Estiú. Buenos Aires, Sudamericana, 1967, pp. 159-165; J. W. Elrod, "Feuerbach and Kierkegaard on the Self", en The Journal of Religion, 56(4), 1976, pp. 348-365; F. L. Jackson, "The New Faith: Strauss, Kierkegaard and the Theological Revolution", en Dionysius, XII, 1988, pp. 111-142. 
la cual ellos dependen, de donde omitimos una tematización explícita de la cuestión.

Por otra parte, los límites de estas páginas nos obligan a asumir una suerte de metodología panóptica, que concentrará y sintetizará las estructuras fundamentales que alienan el pensamiento de Kierkegaard con el idealismo absoluto como escuela filosófica. Un análisis más detallado debería atender de manera desagregada el impacto que sobre Kierkegaard tuvieron los románticos, Schelling, Hegel o el post-hegelianismo de derecha e izquierda. No es este, sin embargo, el espacio de tales análisis sino más bien el de una aproximación introductoria a mayores precisiones y delimitaciones.

Por último, entendemos que la importancia de destacar la consistencia idealista de la metafísica kierkegaardiana no se agota en su novedad historiográfica, sino que apunta a subrayar una lectura de la historia del pensamiento en continuidad esencial. Leer a Kierkegaard como idealista supone, por lo tanto, entender el discurrir filosófico como un despliegue continuo, donde las diferencias pertenecen a una identidad esencial en constante construcción. Del idealismo a Kierkegaard, así como de Kierkegaard en adelante, preferimos leer, en lugar de insuperables disrupciones, serenas y armónicas transiciones.

\section{Una aproximación metafísica al idealismo}

La consideración de Kierkegaard como idealista nos lleva a delinear los rasgos fundamentales de aquel movimiento. Claro está que entre la versión romántica del idealismo y su versión sistemático-hegeliana los matices diferenciales abundan. Sin embargo, en todos los casos se trata de un monismo espiritualista, reflexivo, dinámico y dialéctico, y es esto lo que intentaremos subrayar como determinación común dominante.

Desde el punto de vista histórico, el idealismo se presenta como un proyecto libertario de cuño metafísico, inspirado en la atmósfera espiritual de la Revolución francesa y gestado en dos grandes epicentros: el Seminario Teológico de Tubinga (1788-1793), donde se formaron F. Schelling, F. Hölderlin y F. Hegel; y el Atheneum de Jena (1798-1800), fundado por los hermanos Schlegel y concurrido, entre otros, por F. Schleiermacher, Novalis, J. L. Tieck y F. Schelling. Todos estos autores compartirán el interés por las Lecciones de J. G. Fichte en Jena (1794-1799) y la simpatía por Spinoza. Todos, también, celebraban la llegada del idealismo como "el fenómeno más grandioso de nuestra época", "el espíritu de la revolución" y "la lucha de la humanidad, con todas sus fuerzas, por encontrar su centro". ${ }^{10}$ Tanto en su iniciación romántica como

${ }^{10} C f$. F. Schlegel, Fragmentos. Trad. de Emilio Uranga. México, unAM, 1958, pp. 79-80. 
en su ulterior sistematización hegeliana, en cualquier caso, el idealismo surgía como la conciencia de un nuevo tiempo y una nueva humanidad.

Desde el punto de vista especulativo, por idealismo se entiende una concepción metafísica - no una epistemología ni una teoría del conocimientoque se concibe a sí misma como productora de la razón última de todas las cosas. La clásica identificación idealista de logos y realidad, o bien, de lógica y metafísica supone la unidad de ambas como producto de una especulación -ya sea conceptual, en el caso de Hegel, o estético-religiosa, en el caso del romanticismo-, cuya identidad constituye el punto de llegada de la autoconciencia. La metafísica idealista parte de la autoconciencia, donde la inmediatez del ser es mediada por la reflexión infinita del pensamiento, y concluye en una tercera instancia racional y absoluta, tan real como ideal, tan lógica como concreta y efectiva.

Si para la metafísica idealista realidad y pensamiento son convertibles, su identificación supone la determinación infinita de la libertad, que convierte a la autoconciencia en una acción creadora y a la idea en una realidad efectiva. Por la libertad, el pensamiento se crea a sí mismo, y su idea no designa ni una mera representación abstracta ni una imagen o signo mental, sino "lo que es objeto de la libertad", ${ }^{11}$ vale decir, el sujeto mismo del pensar, asumido como acción, tarea y devenir creador de sí mismo y lo otro. La libertad de la idea abre todas las venas de lo real y produce su carácter infinito, esa infinitud de lo finito que consuma lo ideal.

Otra determinación idealista fundamental consiste en su monismo -herencia spinoziana- espiritual y dinámico. Frente al dualismo sustancialista de la metafísica escolástica, el idealismo recupera el clásico hen kai pan, concebido como una totalidad orgánica y expansiva, pero también dialéctica y diferencial. El uno-todo del idealismo no es, sino que deviene en y por su acción libre y mediadora, que lo multiplica y diferencia. El uno idealista salva la multiplicidad y lo finito en virtud de una concepción de la identidad capaz de contener la negación y diferencia por la mediación dialéctica de sí mismo. El idealismo concibe así "la identidad en la diferencia y la diferencia en la identidad" 12 por la pura mediación de sí, de manera que lo absoluto constituye una categoría reflexiva, cuya identidad es diferencia, cuya afirmación es negación y cuyo devenir es mediación dialéctica de sí mismo.

El uno absoluto se concibe en su propio dinamismo autorreflexivo, que es diferenciación de sí y afirmación del otro. Este devenir sí mismo en y por otro es lo que la Fenomenología de Hegel denomina "sujeto" y concibe como

${ }^{11}$ G. W. F. Hegel, "Primer programa de un sistema del idealismo alemán", en Escritos de juventud. Ed. de José M. Ripalda. Buenos Aires, FCE, 1978, p. 219.

${ }^{12}$ G. W. F. Hegel, Enciclopedia de las ciencias filosóficas en compendio: para uso de sus clases. Trad. de R. Valls Plana. Madrid. Alianza, 2005, \ 118. 
superación de la sustancialidad abstracta e inmediata. Frente al realismo ingenuo de las sustancias autosubsistentes y autofundadas, el idealismo propone un en-sí mediado por su propia acción autoconsciente y libre. De aquí se sigue una de las mayores conquistas metafísicas del idealismo, a saber, la conquista de "la nada", "lo negativo", "la muerte" como determinación dialéctica y mediadora del sujeto absoluto, inmanente a lo uno y productora de su alteridad. La acción libre deviene entonces una acción negativa y la muerte adquiere un rango auténticamente metafísico.

El absoluto idealista está mortalmente herido por una contradicción interior, por una diferencia absoluta, que define su estructura reflexiva e impulsa su fuerza creadora. Porque lo negativo y lo absoluto se implican mutuamente, ello deviene poder creador, y su creación coincide con el acontecer temporal y finito, contingente y relativo de lo uno. El universo y la historia adquieren el valor ideal e infinito de su sujeto, mientras que este último se despliega mortalmente en el tiempo y la finitud. De este modo, los opuestos se escinden y reúnen en el seno de un absoluto, capaz de sostener el desgarramiento de su propia muerte y negación.

Precisamente por su posición mediadora, lo negativo no permanece en sí mismo, sino que se resuelve dinámicamente en una tercera instancia positiva, donde lo absoluto se concibe como tal. El punto de partida y de llegada de la autoconciencia idealista es por eso "el medio", "el centro", "el círculo perfecto" que establece la pura reciprocidad de lo uno. Donde sea que el absoluto se concibe a sí mismo, allí coinciden lo uno y lo otro, en una unidad relacional que mantiene y supera la diferencia. Para usar el nombre más típicamente idealista, este absoluto es llamado "amor", por ser el amor la única relación capaz de conseguir la unidad salvando la diferencia. Se trata aquí de una relación esencial, que hace del sujeto amoroso el objeto mismo del amor.

Por último, el idealismo se caracteriza por la primacía concedida a lo individual o singular, sea este el caso de un individuo existente, de un genio excepcional o del ethos peculiar de cada época y lugar. En cualquiera de ellos, lo individual se concibe como la realización dialéctica y diferenciada del todo, donde lo universal y lo particular, lo infinito y lo finito, la idea y lo real se reconocen mutuamente. Cuando el idealismo asegura que "lo singular es lo real", ${ }^{13}$ se está refiriendo a esa individualidad que ha asumido en sí la totalidad de lo uno y lo otro. El idealismo propone entonces una individualidad sintética, tan universal como particular, pero también eterna y temporal, humana y divina, necesaria y contingente. Lo propiamente idealista resulta la restitución finita y temporal de lo uno, concebida en el seno dialéctico del absoluto mismo, que es proceso de individuación autoconsciente y libre.

${ }^{13}$ Ibid., \ 163. 
En el devenir libre y singular del espíritu, se consuma el desideratum esencial del idealismo, a saber, su intento de construir el "reino de Dios en la tierra" por la realización de lo absoluto en la autoconciencia humana. La existencia se convierte así en el tiempo y el espacio de lo infinito, siempre en lo uno de la diferencia y en el pro-yecto identitario de la contradicción. Dicho en otros términos, la existencia deviene una bildung absoluta: la bildung del espíritu que se hace historia y humanidad a costa de su propio desgarramiento superador.

Una vez revisados los principios que definen la metafísica idealista, consideremos si es esto lo mismo que Kierkegaard objeta por tal.

\section{La crítica de Kierkegaard a un presunto idealismo}

Sabido es que el pensamiento kierkegaardiano está atravesado por una polémica respecto de la cual él buscó confirmarse a sí mismo, a saber, la polémica con un presunto idealismo, interpretado particularmente en clave hegeliana. Tal polémica presenta grandes imprecisiones y vaguedades. En efecto, Kierkegaard rara vez nombra a su interlocutor o referente concreto, y en la mayoría de los casos procede de manera genérica contra "los hegelianos", "la especulación", "la cultura moderna", o simplemente contra "los filósofos" o "la filosofía", como si se tratase de una misma atribución general. La polémica evita los nombres propios, las referencias o los análisis textuales, y ofrece un aspecto más pasional y visceral, que analítico y conceptual.

Pese a la vaguedad de la disputa, lo cierto es que la idea de un Kierkegaard antiidealista y antihegeliano ha ganado la historia de la filosofía contemporánea y se ha instituido en uno de sus lugares más comunes. No caben dudas de que, en cierto sentido, el propio pensamiento de Kierkegaard contribuye a abonar tal presunción generalizada. En efecto, Kierkegaard acusa al sistema de la razón pura -léase, moderna, idealista y hegeliana- de constituir una ficción lógica, que ignora el ser efectivo e hipostasía el ser abstracto. El sistema puramente racional procede por necesidad lógica al despliegue de sus deducciones conceptuales, sin embargo no puede avanzar sobre la existencia que procede con libertad. ${ }^{14}$ De un lado queda entonces la razón abstracta, con su lógica inexorable y sus construcciones deductivas y universales. De otro lado, la existencia concreta, con su acción libre, y su construcción finita y

${ }^{14}$ Cf. S. Kierkegaard, Søren Kierkegaard's Papirer. Ed. de P. A. Heiberg, V. Kuhr y E. Torsting, 2a. ed. Copenhague, Gyldendal, 1909-1948. 20 vols., x ${ }^{3}$ A786/Søren Kierkegaard Skrifter. Ed. de Niels Jørgen Cappelørn et al., Copenhague, 1997-, vol. 24, NB22: 161. 28 vols. 
temporal. Respecto de ésta, el sistema de la razón pura es una ficción, ajena y extraña al orden real. En una palabra, entre razón y existencia no hay medium ni comprensión posible.

Además, el sistema de la razón ignora la existencia individual y establece la universidad abstracta del pensamiento como la sustancia ficticia del todo, de donde se sigue su panteísmo. El panteísmo borra la "diferencia cualitativa" entre Dios y el hombre, y aquí reside la principal objeción de Kierkegaard al pensamiento moderno en general y al sistema hegeliano en particular. Por el olvido de la diferencia, lo universal y lo singular, lo eterno y lo temporal, lo divino y lo humano se confunden en una vaga identidad, vacía de contenido existencial y ético.

Sumado a esto, Kierkegaard le objeta al sistema de la pura razón un comienzo sin presupuestos ni reflexiones preliminares, a partir de un ser pensado y abstracto, idéntico a la nada. Ahora bien, si el sistema comienza con la nada, entonces no comienza nunca y por lo tanto tampoco concluye. El inicio a partir de la negatividad del ser vacío y abstracto significa un no-inicio ni-fin, de donde Kierkegaard concluye que la realidad en la cual termina la lógica no designa ninguna otra realidad más que el ser con el cual aquella ciencia comienza. ${ }^{15}$ Pretender derivar la existencia efectiva por vía lógica, constituye un salto ilegítimo y arbitrario entre dos órdenes inconexos.

Luego de impugnar el inicio del sistema, Kierkegaard critica su clausura en un resultado definitivo que obtura el curso continuo del devenir real. Dado que el pensamiento sistemático piensa su objeto en el ser o en el haber sido, pero no en el devenir, entonces el sistema se cierra sobre sí mismo con una certeza necesaria, pero a costa de renunciar al movimiento continuo de la vida. Ajena a la lógica racional, la existencia prosigue su devenir indetenible, fundado en una contradicción que nunca cesa. Mientras que la causa del devenir existente es para Kierkegaard la diferencia y la contradicción; la causa del movimiento lógico es la "mediación", que anula los opuestos en una suerte de reconciliación abstracta.

Kierkegaard entiende la mediación como una realidad ambigua, que designa tanto la relación entre dos cosas como el resultado de la relación, tanto el movimiento como el reposo del fin. ${ }^{16}$ En cuanto que relación y movimiento, ella se produce en la inmanencia de lo mismo y, por lo tanto, no es jamás un

${ }^{15}$ Cf. S. Kierkegaard, "Begrebet Angest", en Søren Kierkegaards Samlede Varker. Ed. de A. B. Drachmann et al. 2a. ed. Copenhague, Gyldendal, 1920-1936. 15 vols., IV, 320; S. Kierkegaard, Søren Kierkegaard Skrifter, vol. 4, p. 324; S. Kierkegaard, "El concepto de la angustia", en Obras y papeles. Trad. de Demetrio G. Rivero. Madrid, Guadarrama, 1961-1969, vol. vi, p. 49.9 vols.

${ }^{16}$ Cf. S. Kierkegaard, "Begrebet Angest", en Søren Kierkegaards Samlede Varker, vol. IV, p. 319 y S. Kierkegaard, "El concepto de la angustia", en op. cit., vol. vI, p. 41. 
movimiento o relación real, ya que estos suponen siempre una diferencia trascendente. El movimiento inmanente de la mediación deriva de la necesidad del antecedente y es por eso incapaz de producir algo nuevo. Él constituye una categoría lógico-cuantitativa, ajena al devenir cualitativo existente. Por otra parte, en cuanto que resultado y reposo, la mediación concluye en la identidad pura, donde las oposiciones relativas se disuelven en la sustancialidad transparente del todo. Una tal reconciliación abstracta representa para Kierkegaard un modo ingenioso y cómodo de resolver todos los enigmas bajo la noche del absoluto, cuya oscuridad disimula la eterna disolución de lo finito.

Resumiendo, podríamos decir que la lectura kierkegaardiana del sistema de la pura razón -en particular hegeliano, pero en general especulativo, moderno o simplemente filosófico- se corresponde con la de un sistema de la identidad abstracta, intelectualmente panteísta y realmente extraña a la existencia individual. En consonancia con Kierkegaard, tal lectura domina la filosofía contemporánea, ofreciendo la imagen de una disrupción histórica, sin otra continuidad que la de un puro hiato ideacional. No obstante, ella ha conocido también sus objetores. Autores como H. Schmitz, J. Hypollite, J. Wahl, R. Valls Plana o Jon Stewart ${ }^{17}$-para mencionar sólo algunos- se han pronunciado sobre el desentendimiento esencial de la lectura kierkegaardiana, que contribuyó a abonar la leyenda negra del idealismo hegeliano.

\section{Incongruencias de la crítica kierkegaardiana al idealismo}

La crítica a un presunto idealismo, particularmente hegeliano, le permitió a Kierkegaard contra-afirmarse a sí mismo y explicitar, por vía negativa, su propio pensamiento existencial. Sin embargo, que tal polémica valga como crítica consistente y congruente con el idealismo histórico resulta a nuestro juicio, por lo menos, altamente cuestionable. Desde el punto de vista historiográfico, los análisis más rigurosos han mostrado que "Kierkegaard nunca mantuvo la gran polémica con Hegel que los comentadores le han atribuido", ${ }^{18}$ sino que su polémica está dirigida contra el heterogéneo grupo de hegelianos daneses

${ }^{17}$ Cf. H. Schmitz, Hegel als Denker der Individualität. Meisenheim/Glan, Verlag Anton Hain, 1957; J. Hyppolite, Génesis y estructura de la Fenomenlogía del espíritu. Trad. de F. Fernández Buey. 3a. ed. Barcelona, Península, 1998, p. 48; J. Wahl, La lógica de Hegel como fenomenología. Trad. de A. Llanos. Buenos Aires, La Pléyade, 1973; R. Valls Plana, Del yo al nosotros. Barcelona, Estela, 1971, pp. 309, 315 y 385; $C f$. J. Stewart, ed., The Hegel Myths and Legends, p. 16.

${ }^{18} \mathrm{~J}$. Stewart, Kierkegaard's Relations to Hegel Reconsidered, p. 623. La misma tesis en R. Poole, Kierkegaard: The Indirect Communication. Charlottesville, Universidad de Virginia, 1993, pp. 2 y 30-60. 
de su tiempo, y se vale de códigos y seudónimos a fin de mantener ciertas reservas. Lejos de ocupar el primer plano de la academia internacional, sus contrincantes pertenecen a la esfera local, en su mayoría a la jerarquía eclesiástica del protestantismo danés, y el interés personal de la polémica reside antes en una suerte de apologética devocional que en razones de índole filosófica. Por otra parte, desde el punto de vista conceptual, las incongruencias entre lo que Kierkegaard entiende por idealismo, particularmente hegeliano, y lo que éste afirma ser, parecerían abundar.

En líneas generales, la crítica de Kierkegaard al idealismo asume la posición del entendimiento abstracto y finito, cuyo proceder representativo y metafísicamente dualista separa de manera clara y distinta los opuestos que jamás reconcilia, a saber, el ser y el pensamiento, lo real y lo ideal, el tiempo y la eternidad, lo finito y lo infinito, lo humano y lo divino, etcétera. Siguiendo un modelo dualista e intelectualista, Kierkegaard le atribuye al idealismo uno de los términos de la abstracción -lo infinito, lo universal, lo ideal, el pensamiento puro, la razón, el sistema, la necesidad lógica, lo inmóvil, la eternidad, etcétera- con exclusión del término contrario - la finitud, lo individual, la existencia, el pensamiento esencial, el ser, el arte, la posibilidad libre, el devenir, lo temporal, etcétera-, que él reserva para su propia filosofía existencial.

La posición del entendimiento abstracto (Verstand) ha sido históricamente objetada y superada por el propio idealismo, en especial el hegeliano, cuyo proceder especulativo aseguró, contra aquél, la realidad de la contradicción en la inmanencia de una identidad mediada, que el Hegel maduro denominó "razón" (Vernunft) y "concepto", y que el joven Hegel denominaba, al unísono con el romanticismo, "vida" y "amor". La instancia racional del idealismo no condice, por lo tanto, con lo que el intelectualismo kierkegaardiano le asigna. Por el contrario, ella expresa una realidad total, inclusiva de los opuestos y sujeta a una autocontradicción continua, que el entendimiento representativo tiene por paradójica, absurda e imposible. Lo que el entendimiento abstracto excluye por inconcebible, falso, malo, impotente e imposible, la razón lo concibe y contiene en su propio dinamismo absoluto.

El dualismo ingenuo que el idealismo se esforzó por superar reaparece así con un Kierkegaard intempestivo, que parecería ignorar la dialéctica de la identidad romántico-idealista. Tal intelectualismo metódico define y resuelve la crítica kierkegaardiana en el panteísmo de una totalidad indefinida, que ignora y disuelve la singularidad. La identidad que Kierkegaard le atribuye al sistema corresponde a la identidad inmediata y abstracta del entendimiento representativo, ordenado por el principio de no contradicción, según el cual $A$ es $A$ y no puede ser no- $A$. Este tipo de identidad se mantiene ajena a cualquier diferencia, y ajena también a la existencia efectiva, que es siempre una enorme contradicción. 
No obstante, lo cierto es que el idealismo en general y Hegel en particular concibieron la identidad como diferencia absoluta, y el espíritu como el sujeto de su propia contradicción, de manera tal que lo otro coincide con lo mismo y la diferencia vale tan absolutamente como la identidad. Ya que se trata aquí de una metafísica dialéctica, la contradicción de lo absoluto es estructural y estructurante de la conciencia subjetiva, reconocida en y por su propia negación. En este sentido, R. Valls Plana "descalifica la visión kierkegaardiana de Hegel, ya que éste pretende, desde luego, unificar al singular con lo universal, pero no absorberlo. La reunificación, en efecto, es reconocimiento y consolidación de la diferencia absoluta, es decir, de la absoluta alteridad" ${ }^{19} \mathrm{La}$ identidad idealista, que asume en su dinamismo la inmediatez eterna e inmóvil de la identidad abstracta, se realiza como diferenciación activa, temporal y finita, y se proyecta como diseminación continua de sí mismo. De este modo, la idea, que abre todas las venas de lo real, se multiplica y concreta en una repetición sin fin.

Otra objeción de Kierkegaard al sistema de la pura razón consiste en comenzar de la nada, sin presupuestos ni preliminares. Sin embargo, el propio Hegel ha asegurado que el comienzo "es ya por sí mismo una presuposición", ${ }^{20}$ a saber, la presuposición de lo absoluto en y por la acción libre. Para Hegel, y lo mismo vale para el idealismo en general, o bien el comienzo presupone lo absoluto o bien no hay comienzo alguno, y la razón estriba en su concepción circular o enciclopédica del conocimiento real, capaz de producir la totalidad en cada punto y el centro en todas partes. La filosofía empieza y termina siempre en el medio, de manera tal que el sistema repite un absoluto ya puesto y presupuesto en su propia posición. Tal repetición constituye la acción libre del comienzo.

La libertad del comienzo se concibe a sí misma en la idea y de aquí que, para el idealismo, conciencia y acción, teoría y praxis coincidan. Por la libertad, la conciencia es acción efectiva y concreta, de donde el devenir del pensamiento, cuya necesidad deductiva Kierkegaard objeta, resulta ser más bien un movimiento creador, cuyo proceder responde a la implicación ideal de sentidos y significantes. La inteligibilidad pura de la idea avanza entonces libremente, y su sistema tiene menos que ver con el rigor deductivo del intelecto que con la enérgeia productora de la acción libre, fundadora de aquél.

Por otra parte, lo que Hegel denomina "mediación" - a menudo confundida con un tercer estado fijo y subsistente, donde los opuestos se mezclan de manera ambigua o se yuxtaponen sin mezcla ni confusión-constituye en realidad

${ }^{19}$ R. Valls Plana, op. cit., p. 385.

${ }^{20}$ G. W. F. Hegel, Enciclopedia de las ciencias filosóficas en compendio: para uso de sus clases, $₫ 1$ y $\$ 17$. 
un dinamismo reflexivo, que afirma y niega la diferencia por la afirmación y negación de la identidad. El ser y la nada, la esencia y la existencia, lo universal y lo individual, lo eterno y lo temporal son, por la mediación, la pura reciprocidad del uno en el otro, su puro devenir, el centro y el medio de un absoluto que presupone, pone y supera su misma diferencia. Nuevamente aquí, lo que Kierkegaard entiende por la mediación hegeliana correspondería más bien a la representación del entendimiento finito -que fija y distingue, excluye y cierra opuestos relativos- que a la lógica especulativa de la razón, dinámica y dialéctica, inclusiva y siempre abierta. Por eso para Hegel, la mediación repite continuamente el interjuego de la contradicción, donde lo contradicho no son opuestos relativos, sino la identidad misma que los sostiene.

La mediación de lo universal y lo particular, lo eterno y lo temporal, lo absoluto y lo contingente, determina lo que el idealismo llama "singularidad" o "individuo", y comprende en un sentido dialéctico y relacional. La primacía concedida a lo singular poco tiene que ver con el panteísmo abstracto e impersonal que Kierkegaard le atribuye, de donde quizás debería pensarse que lo que este llama "singularidad" se refiere en rigor a algo distinto de lo que el idealismo entiende por tal, a saber, a una construcción de la conciencia subjetiva de índole más bien afectiva, emocional o sentimental, distinta de la construcción metafísica de Hegel. Por lo tanto, no se trataría aquí del olvido idealista de la individualidad frente a su reivindicación existencial, sino de dos niveles de análisis, uno lógico-metafísico, el otro psíquico-patético, ambos implicados en una misma estructura y dinámica fundamental. Podría decirse entonces que tanto Hegel como Kierkegaard "comienzan con la conciencia individual, pero mientras que Hegel comprende esta conciencia lógicamente, Kierkegaard la comprende psicológicamente". ${ }^{21}$ No obstante, el carácter absoluto del espíritu abarca ambos aspectos, sea el plano inteligible e ideal de su desarrollo, sea su intensidad afectiva y patética, porque también en este sentido vale que el espíritu absoluto es mediación.

En una palabra, podría decirse que la crítica de Kierkegaard al idealismo, en particular hegeliano, se sostiene en un malentendido esencial, donde los equívocos abundan y el dualismo dirige la confrontación. El mismo intelectualismo que Kierkegaard encarna en su crítica ha llevado a varios autores a postular la contrapartida de la oposición, vale decir, que Hegel sería el verdadero existencialista, mientras que Kierkegaard permanecería en un subjetivismo arbitrario e infeliz. ${ }^{22}$ No es ésta, si embargo, nuestra opinión. Por el contrario, consideramos que el modelo dualista empleado por la crítica kierkegaardiana

${ }^{21}$ L. J. Start, op. cit., p. 438.

${ }^{22} C f$. Th. W. Adorno, op. cit., pp. 45 y ss.; J. Wahl, Études kierkegaardiennes, p. 451 y L. J. Start, op. cit., p. 434. 
al idealismo y empleado asimismo por la dogmática cristiana que Kierkegaard defiende, no es el paradigma que sostiene su propia metafísica.

Cuando Kierkegaard piensa por y para sí mismo, sin polémicas ni rivales ni clerecías sobre el horizonte, él asume un espiritualismo reflexivo, dialéctico y relacional, muy próximo al idealismo absoluto de sus supuestamente "incomprendidos" interlocutores.

\section{El idealismo de Kierkegaard}

Llamativamente, cuando Kierkegaard se abstrae de la polémica idealista para pensar al individuo singular existente en y por sí mismo, él abandona el dualismo intelectualista utilizado en su crítica y asume el modelo de una racionalidad dialéctico-especulativa, que concibe lo absoluto en los términos reflexivos y diferenciales de la autoconciencia idealista. La filosofía de Kierkegaard presupone entonces los principios metafísicos del idealismo arriba subrayados, a saber: la autoconciencia como punto de partida; la libertad infinita emergida en la idea; la fuerza creadora de lo ideal; la mediación dialéctica del espíritu; la unidad relacional del sí mismo; la singularidad como acción sintética de lo absoluto; y lo absoluto como acción recíproca y amorosa. Brevemente, intentaremos mostrar la consistencia y operatividad de tales principios en el pensamiento kierkegaardiano. Dado que la brevedad de estas páginas no nos permiten un examen exhaustivo de las categorías aquí esbozadas, entendemos lo que sigue como una aproximación a los lineamientos estructurales de la metafísica supuesta por Kierkegaard.

En cuanto a su punto de partida, la filosofía kierkegaardiana parte también de la autoconciencia o, mejor dicho, de la conciencia reflexiva, infinita y negativa de la libertad: comienzo absoluto, que se presupone a sí mismo y no proviene de nada. El concepto de la angustia, de la ironía, de lo inmediato o estético en general expresan este inicio negativo y dialéctico del pensamiento: esa libertad de la cual el espíritu no se puede abstraer. Valga aclarar que el "an sich de la libertad"23 no contiene cualquier comienzo sino el comienzo de un pensamiento real, concreto y creador, en el cual logos y realidad, concepto y fenómeno, idea y existencia están llamados a coincidir en y por el devenir puramente libre de la existencia.

${ }^{23}$ S. Kierkegaard, "Begrebet Angest", en Søren Kierkegaards Samlede Varker, IV, 416; S. Kierkegaard, Søren Kierkegaard Skrifter, vol. 4, p. 410, y S. Kierkegaard, El concepto de la angustia, vol. vI, p. 199. Antes de Kierkegaard, ya Schelling había determinado la libertad como "el concepto positivo del en-sí" (F. W. J. Schelling, Investigaciones filosóficas sobre la esencia de la libertad humana y los objetos con ella relacionados. Trad. de H. Cortés y A. Leyte. Barcelona, Anthropos, 1989, pp. 148-149). 
El origen del pensar es así la libertad, concebida en su "idea" infinitamente posible. Mucho se ha hablado de la "existencia" como categoría nuclear de la filosofía kierkegaardiana, pero muy poco se ha dicho sobre la "idea" o "idealidad" como categoría metafísica que la sostiene y promueve. En efecto, existir es para Kierkegaard la concreción de la idealidad, su manifestación efectiva, a través de un proceso dialéctico que avanza hacia la concreción de lo ideal e infinito en lo real y temporal. La libertad originaria del pensar garantiza así la identidad de ser y conocer; verdad y existencia; origen, proyecto y resultado del pensamiento subjetivo.

Como en el idealismo el elemento ideal contiene la energía activa y creadora de la totalidad, también la idea kierkegaardiana expresa la fuerza concreta del espíritu subjetivo, que lo convierte en objeto de su propia realización. La idea es tanto inteligibilidad y logos, como potencia y posibilidad; ella es "en sí" misma concreta, y, por ello, debe llegar a ser lo que es por su propio devenir efectivo. Una vez que la idealidad surge en la conciencia del sí mismo, su energía se proyecta sobre la realidad fáctica a fin de potenciarla infinitamente y de concretarse en ella.

La doble valencia de la idea, como logos y como poder, como sentido y como fuerza, hace posible el conocimiento propiamente metafísico, que Kierkegaard concibe como un conocimiento real, esencial o existencial, propio del "pensador subjetivo existente". ${ }^{24}$ Este tipo de conocimiento no es un modo de pensar abstracto, sino un modo de ser concreto, cuyo concebir es un producir y cuya conciencia es acción. El pensador existente es, por eso, lo que él sabe, y su saber es la comprensión de sí mismo en la existencia.

Cuando Kierkegaard asegura que "el movimiento en sentido eminente es el movimiento de lo ideal", ${ }^{25}$ lejos está de referirse a un proceso deductivo del entendimiento finito. Por el contrario, él se refiere al devenir concreto de la libertad, cuya idealidad está llamada a consumar el valor infinito de la finitud. Kierkegaard nunca dudó de que "el ideal verdadero es real", ${ }^{26}$ de que "la realidad es la idealidad" 27 y de que "todo progreso hacia lo ideal es un retorno" 28 a

${ }^{24}$ S. Kierkegaard, "Afsluttende uvidenskabelig Efterskrift", Søren Kierkegaards Samlede Varker, vII, 61 y ss./Søren Kierkegaard Skrifter, vol. 7, p. 80.

${ }^{25}$ S. Kierkegaard, Søren Kierkegaard's Papirer, $\mathrm{x}^{3}$ A524/Søren Kierkegaard Skrifter, vol. 24, NB21: 82.

${ }^{26}$ S. Kierkegaard, "Enten - Eller", en Søren Kierkegaards Samlede Varker, II, 227 /Søren Kierkegaard Skrifter, vol. 3, p. 203/"O lo uno o lo otro. Un fragmento de vida II”, en Escritos Søren Kierkegaard. Trad. de Darío González y Begonya Sáez Tajafuerce. Madrid, Trotta, 2000-2010, vol. 3, p. 192. 5 vols.

${ }^{27}$ Cf. S. Kierkegaard, "Afsluttende uvidenskabelig Efterskrift", en op. cit., vII, 313/ Søren Kierkegaard Skrifter, vol. 7, p. 296.

${ }^{28}$ S. Kierkegaard, Søren Kierkegaard's Papirer, $x^{3}$ A 509/Søren Kierkegaard Skrifter, vol. 24, NB21: 67. 
lo originario. En este sentido, también vale para él que lo finito es ideal, porque "la inmediatez se relaciona consigo misma en la idea", ${ }^{29}$ y esta autorrelación produce la identidad recíproca de lo finito y lo eterno. No obstante, lo cierto es que tampoco para Kierkegaard la relación de lo finito y lo ideal procede de manera directa sino dialéctica, y esto significa que su identidad es diferencia y contradicción.

En este punto, se presenta una de las mayores preocupaciones del pensamiento kierkegaardiano, a saber, cómo lograr la reconciliación efectiva de lo ideal y lo fáctico, lo eterno y lo temporal, el pensamiento y el ser, lo absoluto y lo relativo, una vez que la conciencia de la ironía, la angustia, la desesperación y el pecado han mostrado su escisión. A la sazón, la filosofía kierkegaardiana se plantea en torno al mismo problema que el idealismo, a saber, la recuperación de la identidad entre lo ideal y lo fáctico, lo absoluto y lo relativo, lo eterno y lo temporal, cuya diferencia se expresa en la conciencia alienada, infeliz y melancólica de lo absoluto. Al igual que el idealismo, su respuesta negará que tal unidad sea viable en los términos del conocimiento representativo, y exigirá un conocimiento efectivo, creador y metafísico, capaz de identificarlos en el devenir libre de la fe y el amor.

La identidad efectiva de lo real puede y debe ser recuperada, porque tal es el origen uno del espíritu, llamado a convertirse en resultado de su devenir. Sin embargo, esta unidad originaria no es recuperable de manera directa, sino reflexiva y dialéctica, y tal movimiento es lo que se llama "mediación". El espíritu es mediación, y hablamos aquí de mediación porque, también para Kierkegaard, la diferencia de lo uno produce siempre tres, nunca dos, y este tercero expresa tanto la identidad como la contradicción de los términos diferenciados. El espíritu es el dinamismo de su propia diferenciación, la reduplicación de una identidad que finalmente resulta "lo tercero positivo" 30 de la primera identidad, ahora repetida o reduplicada en su propia diferencia temporal, finita y contingente. Esta tercera instancia unificadora asume el carácter diferencial y contradictorio de la identidad idealista, superando tanto la identidad como la diferencia abstractas del dualismo. Contra toda presunción sustancialista e intelectualista, Kierkegaard piensa la identidad espiritual -el sí mismo o la libertad-en términos diferenciales y la diferencia, en términos de autorrelación y acción recíproca. Para él, vale que "la relación es lo absoluto", ${ }^{1}$

${ }^{29}$ S. Kierkegaard, "Stadier paa Livets Vei", en Søren Kierkegaards Samlede Varker, VI, 437/Søren Kierkegaard Skrifter, vol. 6, p. 384.

${ }^{30}$ S. Kierkegaard, "Sygdommen til Døden", en Søren Kierkegaards Samlede Varker, XI, 143-144/Søren Kierkegaard Skrifter, vol. 11, pp. 129-130/“La enfermedad mortal”, en Obras y papeles, vol. vII, p. 48.

${ }^{31}$ S. Kierkegaard, "Enten - Eller", en op. cit., II, 327-328/Søren Kierkegaard Skrifter, vol. 3, pp. 287-288/O lo uno o lo otro. Un fragmento de vida lI, vol. 3, pp. 268-269. 
"lo decisivo", ${ }^{32}$ porque ella determina la existencia y define la singularidad.

Quizás cabe señalar que la filosofía kierkegaardiana es una filosofía dialéctica, estructurada en torno a una diferencia cualitativa que nunca cesa. Sin embargo, con seguridad huelga mucho menos señalar que ella es, por lo mismo, una filosofía de la mediación, o bien, de la segunda inmediatez, flexionada dialécticamente. La primera inmediatez - pura, irreflexiva, estética- es para Kierkegaard una abstracción inexistente e irreal. Lo que existe siempre, en todo lugar y momento, es la mediación de esa identidad inmediata, herida por una diferencia que la niega y la salva. El concepto kierkegaardiano de la "fe" como segunda inmediatez o inmediatez que sigue a la reflexión, así como la categoría de la "repetición" en tanto que segunda potencia de la conciencia, o el concepto de "contemporaneidad" como presencia absoluta, expresan ese dinamismo circular de la existencia, cuya identidad es salvada de su propia contradicción.

Respecto de la categoría de "repetición", varios intérpretes han sostenido su equivalencia con la mediación hegeliana. ${ }^{33}$ Ambas nociones coinciden con el dinamismo reflexivo y reduplicador de lo inmediato, dialectizado por su propia diferencia esencial y recuperado en la segunda inmediatez, que es libertad concreta. Tal como sucede con la mediación, lo tercero positivo de la repetición no es ajeno a su propio repetir, porque no se trata aquí de entidades abstractas sino de un mismo acto libre, cuyo dinamismo concreto une lo imposible de unir para el entendimiento representativo. Tal como sucede también con aquella, el resultado restituye el círculo del origen, luego de haberlo negado absolutamente.

Alguien podría objetar a lo dicho que, si bien es cierto que Kierkegaard aprueba la mediación de términos relativos, él niega sin embargo la mediación de lo que denomina "diferencia cualitativa", ${ }^{34}$ y entiende como la contradicción absoluta representada por la diferencia entre Dios y el hombre. De este modo, la existencia sería capaz de mediar términos opuestos inmanentes a la subjetividad, tales como lo individual y lo universal, el alma y el cuerpo, lo infinito y lo finito, el tiempo y la eternidad, la libertad y la necesidad, pero sería incapaz de mediar su diferencia con el Absoluto mismo, de donde éste permanecería la lejana abstracción de otro totalmente Otro.

${ }^{32}$ S. Kierkegaard, "Afsluttende uvidenskabelig Efterskrift", en op. cit., vII, 397/Søren Kierkegaard Skrifter, vol. 7, p. 371.

${ }^{33} \mathrm{Cf}$. H. Höffding, Søren Kierkegaard. Trad. de F. Vera. Madrid, Revista de Occidente, 1930, p. 70; J. Wahl, "Hegel et Kierkegaard", en Revue Philosophique de la France et de l'etranger. París, Librairie Félix Alcan, 1931, p. 364; J. Stewart, Kierkegaard's relations..., pp. 299 y ss.

${ }^{34}$ Cf. S. Kierkegaard, Søren Kierkegaard's Papirer, v A16; $\mathrm{x}^{2} \mathrm{~A} 296 ; \mathrm{x}^{3} \mathrm{~A} 23 ; \mathrm{x}^{4} \mathrm{~A} 258$; $\mathrm{XI}^{1} \mathrm{~A} 2, \mathrm{XI}^{1} \mathrm{~A} 67, \mathrm{XI}^{1} \mathrm{~A} 495$. 
A esta objeción responderemos que, si tal fuera el caso, la conciencia divina que define a la singularidad y resulta inmanente a la conciencia negativa del pecado sería una ficción intelectual, tanto como lo sería la reduplicación del movimiento amoroso, cuya conciencia salva toda contradicción. Asimismo, si tal fuera el caso, lo divino permanecería tan lejano y extraño como el horizonte remoto de una abstracción irreal, sólo viable al conocimiento directo del entendimiento representativo. En definitiva, Dios y el hombre serían la abstracción sustancial que el mismo Kierkegaard negó que fueran, y el devenir absoluto del espíritu, una vana ficción estética.

La presente objeción nos obliga a precisar el concepto mismo de mediación. En efecto, si la mediación es pensada a partir de las categorías finitas y abstractas del entendimiento representativo, como yuxtaposición o mezcla de sustancias predeterminadas, entonces no hay mediación posible ni entre opuestos relativos ni entre opuestos absolutos. No obstante, si la mediación es pensada como recuperación de lo uno a través de su mismo dinamismo diferencial, entonces puede decirse, con el propio Kierkegaard, que el espíritu es mediación de términos opuestos, por cuya diferencia se relaciona consigo mismo como aquello que es afirmado en y por otro. ${ }^{35}$ En este último sentido, la mediación no significa síntesis de dos sino repetición de lo uno, y su identidad final -su inter-esse o mellembestemmelsen-consiste en el dinamismo creacional de ese "Único, que es Uno y que es Todo", ${ }^{36}$ cuyo devenir es "reduplicación". 37

El absoluto se media a sí mismo a través de una diferencia que lo niega por completo a fin de repetirlo o reduplicarlo en una segunda identidad mediada y determinada por lo otro. En tanto lo tercero positivo, lo absoluto resulta la "pura reciprocidad" 38 de una diferencia reconciliada consigo misma, con su origen indiferenciado e idéntico. Tal identidad constituye, dicho en otros términos, la triplicidad del movimiento amoroso -negación del pecado y restitución de la unidad- que Kierkegaard describe en Las obras del amor como dinamismo omnicomprensivo. En este último sentido, es lo absoluto mismo quien se repite libremente en lo finito, por el único motivo y la sola fuerza de su amor.

${ }^{35}$ Cf. S. Kierkegaard, "Sygdommen til Døden", en op. cit., XI, 143-145/Søren Kierkegaard Skrifter, vol. 11, pp. 129-130/“La enfermedad mortal”, en Obras y papeles, vol. VII, pp. 48-49.

${ }^{36}$ S. Kierkegaard, "Opbyggelige Taler i forskjellig Aand", en Søren Kierkegaards Samlede Varker, vIII, 135/Søren Kierkegaard Skrifter, vol. 8, p. 123.

37 "Dios -dice Kierkegaard- es reduplicación" (S. Kierkegaard, Søren Kierkegaard's Papirer, $\mathrm{XI}^{2}$ A 97).

${ }^{38}$ S. Kierkegaard, "Kjerlighedens Gjerninger", en Søren Kierkegaards Samlede Varker, IX, 433/Søren Kierkegaard Skrifter, vol. 9, p. 377/“Las obras del amor", en Obras y papeles, vol. v, p. 284. 
Entre las nociones adversas que el pensamiento kierkegaardiano siempre rechazó, se encuentra la categoría teológico-dogmática de una divinidad perfecta e inmóvil, cuya eternidad pura trascendiera la imperfección contingente de lo finito y se elevara tras de ello como las montañas azules en el lejano horizonte del tiempo. Al respecto, el esfuerzo de su filosofía consistió en concebir un absoluto dinámico, resultante del devenir subjetivo y siempre sujeto de la acción libre y autoconsciente. De aquí que para Kierkegaard, "Dios mismo es para nosotros este cómo nos ponemos en relación con Él", ${ }^{39}$ bajo el modo de la (neg-) acción de una subjetividad, recuperada en su propia diferencia absoluta. Dios y el hombre, el yo y el prójimo, el Otro y los otros resultan así las abstracciones de una misma identidad diferencial, relacional y recíproca, que Kierkegaard denomina en su sentido más propio "singular" o "individuo" -Enkelte-, por ser éste el lugar de su existencia.

El individuo es la única realidad absoluta, efectiva y concreta, divina y humana a la vez, que el pensamiento kierkegaardiano reconoce. Cualquier otra noción de lo absoluto abstraída de lo singular no pasaría de ser una mera representación ficticia. Esto significa que el singular es tanto el lugar de la unidad absoluta como el lugar de la contradicción de lo absoluto consigo mismo: el lugar de ese "pecado" que trasciende infinitamente al hombre y cuya negatividad solo es salvada por amor. En este sentido, la última determinación posible de la singularidad consiste en su unidad amorosa, donde la identidad escindida resulta siempre tres, nunca dos, y donde lo divino deviene libremente "la pura traducción de tu propia manera de ser" ${ }^{40}$ Esa pura reciprocidad de lo divino y lo humano define al singular como "yo teológico", ${ }^{41}$ transparente a su conciencia absoluta. Y a la sazón, podríamos concluir recordando que también el joven Hegel, en su vena mas romántica, veía al amor como "una duplicación y como unidad concordante de sí misma". ${ }^{42} \mathrm{El}$ amor responde así a este dinamismo reflejo de lo absoluto, capaz de concebirse singularidad.

${ }^{39}$ S. Kierkegaard, Søren Kierkegaard's Papirer, $\mathrm{x}^{2} \mathrm{~A}$ 644/Søren Kierkegaard Skrifter, vol. 23, NB17: 70.

${ }^{40}$ S. Kierkegaard, "Kjerlighedens Gjerninger", en op. cit., IX, 433/Søren Kierkegaard Skrifter, vol. 9, p. 377/"Las obras del amor", en Obras y papeles, vol. v, p. 284.

${ }^{41}$ S. Kierkegaard, "Sygdommen til Døden", en op. cit., XI, 215 / Søren Kierkegaard Skrifter, vol. 11, p. 193/La enfermedad mortal, vol. vII, p. 155.

${ }^{42}$ G. W. F. Hegel, "El amor y la propiedad", en Escritos de juventud, p. 262. 


\section{A modo de conclusión}

Por encima de las polémicas locales y las disputas con el clero dinamarqués, Kierkegaard fue consciente de su momento histórico y del lugar universal de su pensamiento. Él comprendió que "todo el desarrollo del mundo tiende a mostrar la importancia absoluta de la categoría del Singular", ${ }^{43}$ la primacía del "principio de la subjetividad" ${ }^{44} \mathrm{y}$ el viraje reflexivo del pensar, ${ }^{45} \mathrm{y}$ en tal contexto histórico-universal, se entendió a sí mismo como su punto de llegada singular y concreto. Kierkegaard hablaba el lenguaje de los tiempos modernos: el de la libertad absoluta, creadora de sí misma y lo otro, y el desgarramiento del espíritu; el lenguaje de la idea encarnada, y de lo divino hecho tiempo y humanidad. El singular existente, concebido en y por su autoconciencia absoluta, se sabe el legítimo heredero de esta tradición. Él sería impensable desde una metafísica sustancialista y exige ser concebido -subjetivamente- como autorrelación absoluta, repetida en la identidad diferencial de lo divino-humano. El singular kierkegaardiano no es, sino que deviene la bildung inagotable de lo absoluto, siempre abierto a la novedad del tiempo y la historia.

Leemos a Kierkegaard en continuidad histórico-especulativa con el idealismo, pero como un idealista sui generis, a su medida, en el cruce de múltiples distanciamientos y aproximaciones. Con esto no pretendemos decir que Kierkegaard se agote en su raigambre idealista. Por el contrario, el idealismo siempre fue en él una realidad cuestionada por lo que explícitamente entendió ser, a saber, un apologista del cristianismo. En tanto que teólogo ortodoxo llamado a recuperar la autenticidad del cristianismo originario, Kierkegaard debía pronunciarse -dogmáticamente- conforme con la metafísica clásica, intelectualista, binaria y sustancial. Al respecto, era válido y necesario que él defendiera la lógica aristotélica, la trascendencia divina y la dogmática cristiana, tal como suele aducirse, ${ }^{46}$ en contra de un espíritu moderno que, por lo menos desde Kant, amenazaba con disolver la positividad estatutaria de la religión.

Sin embargo, contra el protestantismo dogmático oficial, Kierkegaard sabía también que la permanencia en esa metafísica intelectualista significaba perder para siempre el cristianismo, devorado por su propia objetividad. Y aquí reside la suprema paradoja del pensamiento kierkegaardiano: en su

${ }^{43}$ S. Kierkegaard, Søren Kierkegaard's Papirer, VIII ${ }^{1}$ A9 Søren Kierkegaard Skrifter, vol. 20, NB: 123.

${ }^{44}$ S. Kierkegaard, Søren Kierkegaard's Papirer, $\mathrm{x}^{2}$ A299/Søren Kierkegaard Skrifter, vol. 22, NB14: 121.

${ }^{45}$ Cf. S. Kierkegaard, Søren Kierkegaard's Papirer, $\mathrm{VIII}^{1} \mathrm{~A} 482 ; \mathrm{x}^{2} \mathrm{~A} 6 /$ Søren Kierkegaard Skrifter, vol. 20, NB3: 77.

${ }^{46} C f$. N. Thulstrup y M. M. Thulstrup, eds., op. cit., vol. 4, p. 100, y también N. Thulstrup, Kierkegaards forhold til Hegel og til den spekulative idealisme indtil 1846. 
intento de sostener simultáneamente la dogmática cristiana y la subjetividad absoluta moderna, más aún, de sostener la una mediante la otra. El resultado final fue quedar afuera de ambas, tanto de la Iglesia y la religión oficial como de la especulación idealista.

Frente a tal situación paradojal, es válido y hasta necesario optar por el Kierkegaard que cada uno prefiera. Lo inválido e inconsistente sería no reconocer, en un solo Kierkegaard, también al otro. 